\title{
RESULTADOS DECORRENTES DE INVESTIGAÇÃO DO SISTEMA VISUAL BASEADA NA TEORIA DA SPLIT-FOVEA, APRESENTANDO AS CATEGORIAS DE CONFIGURAÇÃO VISUAL QUE AFETAM A LINGUAGEM E A ESCRITA.
}

\author{
Prof. Dr. Sérgio Luiz Busato \\ Universidade Estadual Paulista "Júlio de Mesquita Filho" \\ slbusato@faac.unesp.br \\ Merielle Claudino Gosmini \\ Universidade Estadual Paulista "Júlio de Mesquita Filho" \\ meri_cla@hotmail.com
}

Resumo: O sistema visual humano usa cerca de $40 \%$ dos neurônios cerebrais para constituir a mais importante fonte perceptiva humana: o sistema visual, que tem suas propriedades investigadas em pesquisas recentes sobre a cognição e a linguagem. São apresentados neste artigo resultados de pesquisa que identificam as possibilidades relacionais entre as direções do olhar e as direções da escrita, constituindo uma ferramenta metodológica que pode instrumentalizar de projetos de design a análises arqueológicas, com aplicações na inteligência artificial, na realidade virtual, no desenvolvimento de games e outros casos em que a visão humana pode ser considerada como a base da cognição.

Palavras-chave: Sistema Visual, Cognição, Linguagem, Design, Emoção.

Abstract: The human visual system uses about $40 \%$ of brain neurons to constitute the most important perceptual human source: the visual system, which has its properties investigated in recent research on cognition and language. In this article are presented research results that identify the relational possibilities between directions of gaze and the directions of writing, constituting a methodological tool that can exploit from design projects to archaeological analyzes, with applications in artificial intelligence, virtual reality, in games development and other cases in which the human vision can be considered as the basis of cognition.

Keywords: Visual System, Cognition, Language, Design, Emotion. 




Gramado - RS

De 30 de setembro a 2 de outubro de 2014

\section{INTRODUÇÃO}

O tema desenvolvido na pesquisa realizada no programa de doutorado em design teve como base estudos do sistema visual, explorando particularmente as implicações cognitivas da teoria da split-fovea, que trata de um detalhe anatômico da fisiologia visual: a divisão vertical de cada olho através da fóvea, de onde ligações neurais separadas direcionam os sinais visuais aos dois lados do cérebro. Fundamentando a pesquisa na ciência cognitiva, foram buscadas inter-relações nas disciplinas que a compõem: Filosofia, Semiótica, Inteligência Artificial, Psicologia, Antropologia e Neurociências, as quais, de forma complexa participam do processo cognitivo. Os resultados da pesquisa nos possibilitaram concluir que essa característica visual tem ação determinante nos resultados cognitivos, devido aos hemisférios cerebrais terem características específicas de processamento, que efetuam abordagens diferentes de um mesmo fato perceptivo. (Busato, 2013). Uma das áreas importantes afetada por este detalhe do sistema visual, que aqui exploramos, é a escrita. Para entender completamente esta relação sígnica, julgamos relevante iniciar pela história da escrita, observando seu surgimento e evolução, seguido de uma análise da seta do tempo, que está na base do processo da semiose, para então, usando a metodologia de matriz gerativa, relacionar as categorias de configuração visual que condicionam as direções da escrita.

Apontamos no artigo exemplos de configurações visuais, expressas em obras e produtos de culturas diferentes, associando-os às direções indicadas pela pesquisa. Concluímos, usando conceitos da Psicologia e da Semiótica, identificando sob que condições o signo se associa à cognição e à emoção.

\section{HISTÓRIA DA ESCRITA}

Uma questão inicial necessária ao abordar a escrita, diz respeito à prevalência entre a escrita e a leitura, "o que vem primeiro?". Sobre isto esclarece-nos Vilém Flusser:

\footnotetext{
"A sã compreensão humana (que, como se sabe, nunca tem razão) assegura que o escrever antecede o ler, para se poder ler, algo tem de ser escrito. Não é exatamente assim. Mesmo muito antes da escrita, já se lia (tomemos, por exemplo, escolher ervilhas). O próprio escrever é apenas um modo de leitura: os sinais gráficos são escolhidos (lidos) dentre uma porção, de maneira semelhante ao que se faz com as ervilhas, para serem dispostos em linhas. Ler (legere, legein) significa escolher (Herauspicken), selecionar (Klauben)" (Flusser, 2010, p. 91).
} 
Por tratarmos tecnicamente a escrita neste trabalho, adotamos o conceito de Vilém Flusser (2010) usando, sempre que adequado, o conjunto "leitura/escrita" ao nos referirmos à escrita, sem privilegiar esta ou aquela.

Desde sua origem, a expressão do pensamento e sua transmissão utilizaram as formas de várias maneiras. Inicialmente através dos gestos e da linguagem corporal, acompanhados de vocalização, de caráter emocional direto, que com o passar do tempo se consolidou em linguagem falada, sendo usada dentro de grupos com as mesmas experiências e repertórios linguísticos. Em determinado momento da sua evolução o Homem começou a traçar sinais mnemônicos, primeiro no fundo de cavernas, com significado mágico e depois fazendo inscrições em pedras e tabletes de barro (clay) que eram posteriormente secos, ou cozidos para uma gravação permanente (Mandel, 2011).

Estudiosos da escrita acreditam que ela iniciou com a contabilidade, apesar de poucas amostras restarem dessa atividade, no que sobreviveu das escritas egípcia, chinesa e da América Central. Tabletes sumerianos indicam que ela se desenvolveu como consequência direta das demandas de uma economia em expansão, atendendo as necessidades dos registros e administração das primeiras cidades mesopotâmicas, que teriam alcançado um ponto que excedeu a capacidade de memória da elite governante e mercadores. Tornou-se essencial para o armazenamento de transações de forma permanente, em contraste com a volatilidade da palavra falada (Robinson, 2007).

Alguns dizem que a escrita foi o resultado de uma busca consciente de um indivíduo sumério desconhecido da cidade de Uruk em cerca de 3.300 a.C. , outros acreditam que foi trabalho de um grupo, presumivelmente de administradores e mercadores. Outros ainda pensam que não houve uma invenção, mas uma descoberta acidental. Muitos a consideram mais resultado da evolução durante um longo período do que um lampejo de inspiração. Uma das teorias sustenta que ela teria surgido ao longo de um sistema de contagem em sinais de barro, de propósito desconhecido, encontrados em sítios arqueológicos do meio leste (Robinson, 2007).

Os primeiros símbolos da escrita foram símbolos icônicos - pictogramas, representações pictóricas de objetos concretos, lidos como ideogramas e que aos poucos foram sendo estilizados. Seu ponto de partida: os sinais mnemônicos mágicos, assim como as marcas de propriedade.

"O encadeamento de sinais mnemônicos é o esquema de um discurso, pela sucessão apresenta elementos de ideias ainda não expressas". (...)

"O poder mágico da palavra pronunciada, carregada de significado, passa para a escrita e passa a valer como "realidade". Está escrito..." (Mandel, 2011 p.17). 




Gramado - RS

2014

De 30 de setembro a 2 de outubro de 2014

A abundância do pensamento faz com que este ao passar para a linguagem oral sofra uma seleção e linearização das palavras, que se sucedem para revelar um "sentido", sofrendo nesse processo um empobrecimento. A este reducionismo de conteúdo se procura enriquecer com a linguagem corporal e a elocução da palavra falada. Ao passar da linguagem oral para a linguagem escrita há nova redução, já que a escrita não incorpora a linguagem gestual e de entonação. Da mesma forma o escriba, o tipógrafo e o designer tentam compensar a parte afetiva e emocional contida na linguagem oral, através do uso da pontuação, da adequação do estilo das fontes, das cores e das dimensões.

Karl Popper (1999, p. 121) reconhece na linguagem duas funções principais: a descritiva e a argumentativa, e algumas funções inferiores, que compartilhamos com animais: auto-expressão e sinalização, que liberam resposta no outro organismo. Da função descritiva emergem: ideias reguladoras da "verdade", descrições que se ajustam aos fatos; conteúdos de verdade e verossimilhança. Diz que "sem linguagem descritiva exossomática não há objeto para a descrição crítica", e sobre a linguagem argumentativa, que "o poder de raciocinar está nos poderes de argumentação crítica".

O essencial para o surgimento da escrita em sua totalidade, ao invés da pura representação pictográfica, foi a descoberta do princípio do REBUS, que foi a ideia paradigmática de que um pictograma ou símbolo gráfico podia ser usado pelo seu valor fonético (Robinson, 2007).

Os operários e mercadores nômades semíticos converteram a escrita egípcia para a escrita alfabética, retendo alguns sinais de valor fônico e decompondo a linguagem falada em certo número de fonemas. Segundo os historiadores, os gregos foram os herdeiros do alfabeto fenício por volta de 900 a.C., tendo o transmitido aos etruscos, que por sua vez o passaram aos romanos. Constata-se que no século VII a.C. as escritas grega, etruscas e romanas tinham em sua forma arcaica grande semelhança com a fenícia. Os gregos ao adaptarem o alfabeto semítico de sinais às suas particularidades linguísticas e culturais retiveram o valor fônico sem manter as relações icônicas, o que os tornou "símbolos" fonéticos mais abstratos, favorecendo a combinação sonora (Mandel, 2011). Essa liberdade em relação ao valor pictórico da origem do caractere reforça a premissa da arbitrariedade dos signos linguísticos postulada por Saussure (2006). 




$$
\text { Gramado - RS }
$$

De 30 de setembro a 2 de outubro de 2014

\section{Alfabeto Acrofônico}



Figuras 1 e 2 - Evolução de alguns pictogramas, do figurativismo à abstração e alfabetos resultantes (Adaptado de Mandel, 2011).

Alfabeto Hieroglífico Básico:
A
$\mathrm{H} \xi$
$\mathrm{N}-\mathrm{U} \mathrm{B}$
B \& I I
$O$ की $V$ a
$C$ oouf $\mathrm{J}^{2} \mathrm{C}$
$P \square W$ \&
$\mathrm{D} \Leftrightarrow \mathrm{K} \propto$
$\mathrm{Q} \Delta \quad \mathrm{X} \sim \mathrm{P}$
E A4 oun o 4
$\mathrm{R} \odot \mathrm{Y} A \mathrm{~A}$ ои 1
$F \times$
$L$ is $\mathrm{S}$
$\mathrm{Z} \rightarrow$
G 因
$\mathrm{SH} \square$

Figura 3 - Alfabeto em hieróglifos (Adaptado de Mandel, 2011). 
Livrando o alfabeto das características semíticas icônicas, os gregos deram a ele uma dimensão universal, permitindo transcrever qualquer língua por meio de um único conjunto de sinais, construídos a partir de formas abstratas geométricas como o círculo, o quadrado, o triângulo e outros elementos, ocupando espaços modulares contínuos e alinhados, que expressavam a clareza e a simplicidade da ordem grega, que refletia a sabedoria e a lógica platônica. A direção da escrita é ainda incerta, sendo as mais antigas da direita para a esquerda e depois da esquerda para a direita, no chamado bustrofédon, ou à maneira de um boi atrelado ao arado, que segue em um sentido e retorna arando no sentido oposto. A escrita da esquerda para a direita popularizou-se por causa da escrita manuscrita com tinta, ao apresentar a vantagem para os destros, de não borrar o que se escrevia e poder ver o que acabava de se escrever (Mandel, 2011).



Figura 4 - Escrita grega em bustrofédon - Leis de Gortina - Grécia. Fonte: Revista Rambla, disponível on-line em http://www.revistarambla.com/v1/ocio/viajes/1219-las-leyes-de-gortina

\section{A SETA DO TEMPO}

Para escrever, dispondo em sequências os sinais que representam os sons, é necessário ocupar algum espaço durante a escrita, pois que a continuidade obriga a seguir em alguma direção. Esta questão por trivial que possa parecer, remete à questão filosófica do que é o tempo e para onde aponta sua seta. Alguns postulados da Física podem ser úteis para a compreensão, já que o tempo é um componente da existência do Universo, desde a origem e durante toda sua evolução. A teoria da relatividade geral de Einstein combina o tempo real e as três dimensões do espaço em um espaço-tempo quadridimensional, sendo a direção do tempo diferenciada das três direções espaciais (Hawking, 2001). Em "Uma breve história do tempo", Hawking (1988), assim descreve a seta do tempo:

"O aumento da desordem ou entropia através do tempo é um exemplo do que se chama uma seta do tempo, algo que distingue o passado do futuro dando a 




Gramado - RS

2014

De 30 de setembro a 2 de outubro de 2014

direção do tempo. Existem pelo menos três setas de tempo. Primeiro há a seta do tempo termodinâmica, a direção do tempo em que a desordem ou entropia aumenta. Depois há a seta psicológica do tempo; esta é a direção em que sentimos o tempo passar, a direção em que nos lembramos do passado, mas não do futuro. Finalmente existe a seta cosmológica do tempo, que é a direção do tempo em que o Universo se expande mais do que se contrai" Hawking (1988, p. 201).

Prigogine trabalhou o conceito das estruturas dissipativas na Termodinâmica, nas quais reconhece que há um mecanismo, em que elementos de um sistema podem agir sobre grandes regiões do mesmo, e faz associação entre essas propriedades e o conjunto das regras gramaticais. A concepção do tempo, de Prigogine, inclui um tempo interno dos sistemas, como medida de complexidade, e fala de terceiridade no sentido peirceano, existindo nos processos de sinergia e nas correlações de grande alcance. Sob esse ponto de vista, Santaella (1992) faz esta referência:

"Ora o que Prigogine chama de tempo, Peirce chamava de semiose (ação do signo). Aliás, o tempo não é outra coisa senão o desenrolar-se da semiose, processo autogerativo de signos, signos gerando signos e sendo gerados de signos" (Santaella, 1992, p. 144).

A concepção do tempo também pode ser esclarecida a partir dos vários conceitos de eixos do tempo, e considerada de maneiras diferentes, mostrando sua relatividade. Em um ensaio sobre o tempo, Santaella destaca os seguintes pontos:

- Semiose como ação sígnica está associada ao conceito de ação inteligente.

- Semiose está também associada ao conceito de tempo irreversível.

- Semiose faz parte da constituição sistêmica da realidade, na medida em que sistemas imersos no universo mantêm contato com este, participando de uma termodinâmica universal (Mende \& Peschel, 1981 apud Santaella \& Vieira, 2008).

Santaella usa como referência teórica a discussão de Gal-Or (1975) compatível com a proposta de Prigogine e de Mende \& Peschel sobre o tempo irreversível e questões associadas, que definem a noção da existência de três eixos do tempo: 0 primeiro, de acordo com a astrofísica, o Master, seria causado pela assimetria temporal causada pela expansão do espaço. O segundo eixo cosmológico, poderia ser definido pela temperatura ou densidade de radiação decrescente, em um mundo em expansão. O terceiro seria ocasionado pelo fluxo direcionado de energia de radiação da superfície de todos os sistemas galáticos para o espaço em expansão, frio e não refletor. Essa proposta pode ser interpretada como: O processo Master decorre da expansão do Universo, originada de um Big-Bang e associada à singularidade inicial. Essa expansão exige energia do Big-Bang que é sugada do Universo gerando entropia, 




Gramado - RS

2014

De 30 de setembro a 2 de outubro de 2014

necessitando para seu escoamento dos mecanismos dissipativos, aos quais estão associados o primeiro e o segundo eixo.

"A matéria em evolução comporta-se como um sistema de canais por onde escoa a energia e é produzida a entropia" (Santaella \& Vieira, 2008).

Seria a partir do terceiro eixo do tempo, o da termodinâmica dos sistemas intragaláticos que a vida surge no nosso sistema planetário, demarcando outros eixos do tempo, como um quarto, o tempo biológico e a partir da complexidade crescente um quinto eixo - o tempo psicológico e da consciência, que determinam o eixo sígnico - Tempo da Semiose. Os vários eixos do tempo conduziriam a uma produção crescente de complexidade, indicando que o Universo parece evoluir por meio de um fluxo não linear de complexidade. Segundo Santaella \& Vieira a semiose, que hoje consideramos como característica das coisas vivas e humanas está associada em sua evolução ao surgimento e evolução do Universo. Concluem frisando que os vários eixos do tempo têm caráter de irreversibilidade e todos eles apontam para uma mesma direção: o futuro (Santaella \& Vieira, 2008). Concluímos nesta seção, que devemos considerar o tempo como eixo sígnico, experimentado em condições de relatividade nas esferas pessoal, socioambiental e universal. A geração dos signos ocorre no tempo da semiose, permitindo ao indivíduo interpretar o mundo em uma representação interna dinâmica, comparativa entre o momento anterior, o presente e a projeção de um futuro probabilístico, interpretante emergente da representação.

\section{A DIREÇÃO DA ESCRITA}

Direção da escrita é o conceito que utilizamos para relacionar a expressão do pensamento através da representação simbólica no Eixo do Tempo. Não particularizamos neste estudo das direções da escrita, os efeitos advindos da correspondência das conexões entre as hemirretinas e os hemisférios cerebrais, o que implicaria em identificar como os hemisférios processam as informações em cada configuração possível e as preferências hemisféricas para o que é visto.

Quando associamos a fisiologia do sistema visual à maneira como se processa a leitura/escrita no Eixo do Tempo, ou ao longo da Seta do Tempo, podemos relacionar a escolha das direções como limitadas às possibilidades perceptivas que identificamos no tópico 5 , e concluímos que os sistemas de leitura/escrita necessariamente devem se enquadrar nas suas categorias. Associando a Teoria Semiótica da Percepção à configuração visual que intermedia a representação sígnica, a identificamos como da ordem do percipuum, objeto imediato da percepção, por sua relação física, sensorial, de ligação entre o percepto e o interpretante. 


\section{CATEGORIAS DE CONFIGURAÇÃO VISUAL}

As categorias que identificamos ao considerar a divisão fisiológica da fóvea humana comportam configurações limitadas, que podem ser mapeadas em uma matriz assim desenvolvida:

Considerem-se as direções possíveis como sendo: $(-1) \Leftarrow$ à esquerda, $(0) \widehat{\prod}$ acima, abaixo ou à frente e $(+1) \Rightarrow$ à direita. Podemos encontrar para cada olho as combinações:

\begin{tabular}{|c|c|}
\hline $\begin{array}{c}\text { Olho } \\
\text { Esquerdo }\end{array}$ & $\begin{array}{c}\text { Olho } \\
\text { Direito }\end{array}$ \\
\hline $0 \quad 0$ & $0 \quad 0$ \\
\hline $0+1$ & $0+1$ \\
\hline $0-1$ & $0-1$ \\
\hline-10 & -10 \\
\hline$-1+1$ & $-1+1$ \\
\hline$-1-1$ & $-1-1$ \\
\hline+10 & +10 \\
\hline$+1+1$ & $+1+1$ \\
\hline$+1-1$ & $+1-1$ \\
\hline
\end{tabular}

Figura 5 - Matriz de configuração da direção de leitura/escrita. (Elaborado pelo autor, com base na pesquisa realizada).

Onde o olho, por ser dividido em duas metades verticais (split-fovea), direciona os sinais de cada lado para um lado diferente do cérebro, e pode suportar as direções:



Figura 6 - Olhos com as configurações possíveis da direção de leitura/escrita e conexões hemisféricas (Elaborado pelo autor, com base na pesquisa realizada). 




$$
\text { Gramado - RS }
$$

De 30 de setembro a 2 de outubro de 2014

Obtendo como configurações possíveis, as que apresentam simetria entre os dois olhos:


Figura 7 - Desenvolvimento gráfico da matriz de configuração das direções de leitura/escrita nos olhos esquerdo e direito respectivamente (Elaborado pelo autor, com base na pesquisa realizada).

Eliminamos, como improváveis, as configurações que direcionam a hemi-visão de cada olho para total oposição com seu par, por considerá-las conflitantes e antiergonômicas, mantendo as relações com sincronia entre os dois olhos, obtendo assim as configurações mais prováveis:


Figura 8 - Configurações mais prováveis das direções de leitura/escrita. (Elaborado pelo autor, com base na pesquisa realizada). 




$$
\text { Gramado-RS }
$$

De 30 de setembro a 2 de outubro de 2014

Estas configurações resultantes podem ser inter-relacionadas, ocorrer de forma intercalada ou simultânea e têm compatibilidade com as direções de escrita pesquisadas, tanto do Oriente quanto do Ocidente, correspondendo, por exemplo, às escritas:



Escrita/leitura de ideogramas, primitiva.



Chinês= Mar



Celta-Irlanda

\section{Escrita/leitura ocidental}

CVMQVODAMCA

AS REGIONIS PINEF

OOICIS LAERANEN

SRELIQVIT EASY

NONIASIGVLISÄN

II TTRFS MISS



À esquerda: Escrita Romana - Latim.

Ao lado: Livro em Português.

Figura 10


Escrita Ocidental no sentido vertical.

Figura 11



Escrita/leitura - Árabe e Indiana



Nome Sérgio em árabe.

Índia-Inscrição do brasão de armas: "Só a verdade vencerá".

Figura 12 




Gramado - RS

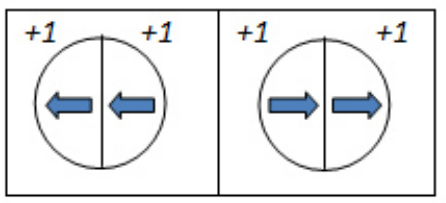

Egito - Escrita hieroglifica

dupla direção de escrita/leitura a partir do centro.



Escrita/leitura egípcia

dupla direção de escrita/leitura a partir do centro.

Figura 13


Egito - Escrita hieroglífica com dupla direção de escrita/leitura vertical/bilateral.

Figura 14

Figuras 9 a 14 - Identificação da direção de leitura/escrita em culturas diversas. (Elaborado pelo autor, com base na pesquisa realizada - Fotos: Busato, 2008 e 2011)

Observamos em diversos sistemas de escrita, que muitas vezes mais de uma configuração direcional ocorre dentro do mesmo sistema, ratificando a observação de Allport (1991) que cita sete referências confirmando essa possibilidade:

“...está claro, que o cérebro é capaz de manter representações independentes com interferência mínima entre elas, no controle de categorias separadas de codificação e ação" (Allport, 1991, p. 638).

No caso dos hieróglifos, estes têm a particularidade de permitir a leitura/escrita em várias direções: direita-esquerda, esquerda-direita simultâneos, só esquerdadireita, só direita-esquerda e distribuída em barras horizontais e verticais. A escrita alfabética também pode ser arranjada em disposição diferente da tradicional esquerda-direita, como vertical e inclinada, consideradas críticas na área gráfica e publicitária, por dificultar a leitura do texto. Ocorrências como essas nos levam a reconhecer duas possibilidades: que ler em direções não usuais pode tratar-se de uma habilidade cognitiva pré-existente ao sistema linguístico, como gostariam os nativistas e gestaltistas ou adquirida culturalmente, assim como uma pessoa aprende outra 


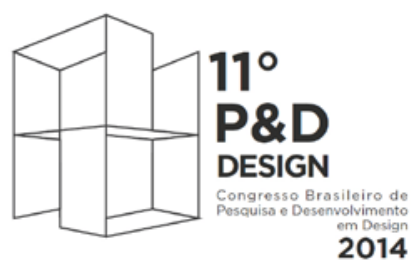

Gramado - RS

2014

De 30 de setembro a 2 de outubro de 2014

língua ou adapta-se a outra cultura, ao sabor dos empiristas e construtivistas (Santaella, 1998). Sem pretensão de escolher entre elas, optamos por considerar a possibilidade complexa da dupla ocorrência.

\section{CONCLUSÃO}

Investigadas as inter-relações da visão com as ciências cognitivas, recorremos aos estudos da Psicologia sobre a atenção, que sustentam que seus mecanismos detêm o controle sobre o foco da visão, escolhendo seu objeto e como este será observado (Eysenck, Keane, 2007). A partir daí os dados visuais conduzidos aos hemisférios cerebrais com processamento diferenciado, são convertidos em signos multiarticulados integrando os processos da representação, da consciência e da ação. A emoção, componente bio-psicofisiológico do signo, determina a relevância da percepção para o sujeito, manifestando-se em diversos graus de valor, que correspondem a níveis de sobrevivência, de valores socioambientais e de sentimentos pessoais, agregando-se ao "signo para o sujeito", o que the atribui valores de afetividade positiva ou negativa, pela associação com marcadores biológicos eletroquímicos, originados de reações individuais conscientes e inconscientes (Norman, 2004). A utilização dos dados da pesquisa no desenvolvimento de projetos ou como meio de rastrear a atividade visual, associando-a à escrita/leitura, é compatível com as novas metodologias de Design e Emoção, fundamentadas em fatores biológicos, usadas com a intenção de favorecer a afetividade positiva em relação aos produtos; ou ainda utilizada como recurso de simulação do real, ao reproduzir virtualmente em equipamentos os mecanismos perceptivos cerebrais.

\section{REFERÊNCIAS}

ALLPORT, Alan - Visual attention - in: Posner, Michael I. (Ed), (1991). Foundations of cognitive science, (pp. 631-682). Cambridge, MA, US: The MIT Press, xiv, 888 pp.

BUSATO, Sérgio Luiz. Tese de doutorado "Visão e Percepção: Investigação dos modelos cognitivos - Uma abordagem neurobiológica em Design e Emoção." Universidade Estadual Paulista. Faculdade de Arquitetura, Artes e Comunicação, Bauru, 2013.

BUSATO, Sérgio Luiz. Fotografias: Egito e Museu do Cairo - Nikon D200, janeiro 2011.

BUSATO, Sérgio Luiz. Uma nova forma de ler a escrita egípcia. In: ENSAIOS EM DESIGN - arte, ciência e tecnologia. 1ed. Bauru: canal 6 editora, 2010, v. 1, pp. 144-169.

BUSATO, Sérgio Luiz. Uma nova forma de ler a escrita egípcia. Anais do WAC 6, World Archaeological Congress, Dublin, Ireland, 2008. 


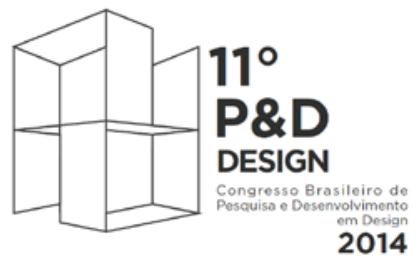

Gramado - RS

2014

De 30 de setembro a 2 de outubro de 2014

ANDREW W. BRYSBAERT, Marc. Split fovea theory and the role of the two cerebral hemispheres in reading: A review of the evidence. Neuropsychologia, Jan, 2010, Vol. 48(2), p. 353(13) Portal de Periódicos CAPES.

ANDREW W. BRYSBAERT, Marc. Divided Opinions on the Split Fovea Neuropsychologia. 2010, Vol.48 (9), pp. 2784-2785.

EYSENCK, Michael W.; KEANE, Mark T. Manual de Psicologia Cognitiva. 5a. Porto Alegre: Artmed, 2007.

FLUSSER, Vilém. A Escrita - Há futuro para a escrita? Trad. Murilo Jardelino da Costa, São Paulo: AnnaBlume, 2010.

GaL-Or, B. Philosophical Problems in Thermodynamics. In Entropy and_Information in Science andPhilosophy. Kubat, L, Zeman, J., Ed., 211-230. Praga: Elsevier Sci. Publ. Co.(1983). Cosmology, Physics andPhilosophy. New York: Springer-Verlag.

HAWKING, Stephen. Uma breve história do tempo. Trad. Maria Helena Torres, 262 págs., Rio de Janeiro: Rocco, 1997.

HAWKING, Stephen. 0 Universo numa Casca de Noz. Trad. Ivo Korytowski, 215 págs., São Paulo: Mandarim, 2001.

MANDEL, Ladislas. O poder da escrita. Trad. Constância Egrejas, São Paulo: Rosari, 2011.

MARTIN, Clara D., THIERRY, Guillaume, DÉMONET, Jean-François, ROBERTS, Mark, NAZIR, Tatjana, 2007. ERP evidence for the split fovea theory. Brainresearch 1185 (2007) 212 - 220 disponível on-line at www.sciencedirect.com, acesso em 06 Abril 2011.

Mende, W. e Peschel, M. (1981 a). Projeto da estrutura de sistemas não estacionários e não-lineares. Messen-Steuern-Regeln (MSR), 24 (10): 581-583 (em alemão).

NORMAN, Donald A. Emotional Design: Why We Love (Or Hate) Everyday Things. New York: Basic Books, 2004.

PEIRCE, Charles Sanders. In: Os Pensadores - Pierce/Friege. São Paulo: Nova Cultural, 1989.

POPPER, Karl. Conhecimento Objetivo - Uma abordagem evolucionária. Trad. Milton Amado, Belo Horizonte: Itatiaia, 1999.

ROBINSON, Andrew. The Story of Writing. 232 págs., London:Printed in Slovenia, Thames \& Hudson, 2007.

SANTAELLA, Lúcia e VIEIRA, Jorge Albuquerque. Metaciência como guia da pesquisa. São Paulo: Mérito, 2008.

SAUSSURE, Ferdinand de. Curso de Linguística Geral. Org. Charles Bally, Albert Sechehaye, colab. Albert Riedlinger, São Paulo: Cultrix, 2006. 